\title{
LBNE LatTice \& Optics For Proton Extraction at MI-10 AND Transport to a TARget ABOve Grade
}

\author{
JOHN A. JOHNSTONE
}

\begin{abstract}
For the Long Baseline Neutrino Experiment (LBNE) at Fermilab $120 \mathrm{GeV} / \mathrm{c}$ protons will be transported from the Main Injector (MI) to an on-site production target. The lattice design \& optics discussed here has the beam extracted vertically upwards from MI-10 and the keeps the majority of the line at an elevation above the glacial till/rock interface and terminates on a target at $10 \mathrm{ft}$ above grade.
\end{abstract}

\section{Design Layout}

Protons are extracted from the Main Injector (MI) in the MI-10 straight section. The extraction magnets are of the standard MI design and complement -3 kicker modules at the upstream end of the MI-10 straight to kick the beam horizontally into 3 vertically bending Lambertsons plus a C-magnet straddling MI quad Q102 located $90^{\circ}$ in betatron phase downstream. A single, rolled, long $(6 \mathrm{~m})$ MI-style IDA/IDB dipole [1] steers the beam horizontally towards the MI enclosure wall between MI quads Q105 \& Q106, while leveling the beam off somewhat to a gentle vertical slope of $+0.60^{\circ}$, thereby bisecting the space separating the MI \& Recycler Ring magnets. A $15.6 \mathrm{~m}$ long carrier pipe transports the beam through the MI tunnel wall into the new LBNE enclosure that houses the main body of the line. From that point the protons are transported a further $305.4 \mathrm{~m}$ to the LBNE target, located $10 \mathrm{ft}$ above grade (750 ft above sea level) and aimed towards DUSEL. In the main body of the LBNE line bending is provided by 12 IDA/IDB plus 12 short $(4 \mathrm{~m})$ MI-style IDC/IDD dipoles $\left(-7.180^{\circ}\right.$ horizontally and $-5.789^{\circ}$ net vertically). Bends are grouped into twelve $4+6 \mathrm{~m}$ pairs. The first 3 cells in the LBNE tunnel accomplish the horizontal alignment to DUSEL while generating a $+150 \mathrm{mr}$ vertical trajectory. This upwards trajectory continues through the 3 subsequent empty FODO half-cells, followed by 3 full cells that create the $251 \mathrm{mr}$ of down bend necessary to obtain the final $-101 \mathrm{mr}$ trajectory alignment to DUSEL. Maximum beam elevation is $40 \mathrm{ft}$ above grade. Optical properties are defined by 24 quadrupoles (grouped as 23 focusing centers) of the proven MI beamline-style 3Q60/3Q120 series [2]. All focusing centers are equipped with redesigned MI-style IDS orbit correctors [3] and dual-plane beam position monitors (BPM's) [4]. Ample space is available in each cell to accommodate ion pumps and diagnostic instrumentation. Parameters of the main magnets are listed in Table 1.
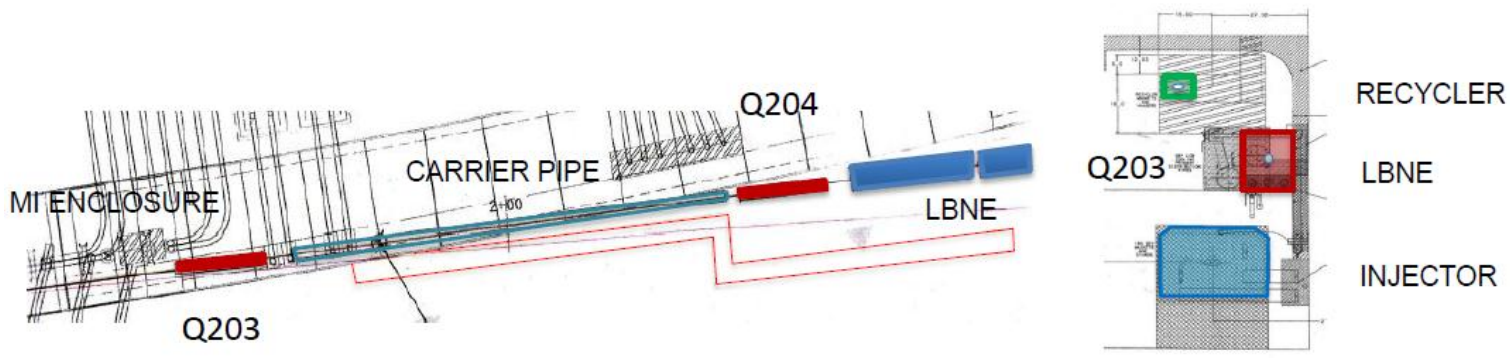

Figure 1: Transport from the existing MI tunnel enclosure into the new LBNE enclosure Carrier pipe connecting the MI-10 \& LBNE enclosures (left), and separation of Q203 at the u/s end from the MI \& Recycler Rings (right). 


\section{Optics}

This $60 \rightarrow 120 \mathrm{GeV} / \mathrm{c}$ transfer line design is comprised of distinct optical modules, as illustrated in Figure 2:

- An extraction plus matching section from the MI into the main body of the LBNE FODO lattice.

- A periodic series of 6 FODO cells $(185.15 \mathrm{~m})$. This section includes a $-125 \mathrm{mr}$ horizontal and $+150 \mathrm{mr}$ vertical combined-plane achromat at the upstream end, plus a $-251 \mathrm{mr}$ vertical achromat formed by the last 3 cells.

- A widely tunable triplet final focusing module to control beam size on the target.

The first six quadrupoles in the LBNE beamline are powered individually to perform the optical match between lattice functions of the MI and those of the LBNE transfer line [the roll angles of dipoles in the first 3 half-cells are selected specifically to contribute to the dispersion matching of $\left.\left(\eta_{\mathrm{x}}, \eta_{\mathrm{x}^{\prime}}\right) \&\left(\eta_{\mathrm{y}}, \eta_{\mathrm{y}}{ }^{\prime}\right)\right]$. This matching section is followed by six $120^{\circ}$ FODO cells characterized by quadrupoles Q207 through Q218. Cell length and phase advance are chosen such that beam size does not exceed that of the MI $90^{\circ}$ lattice cell structure, while also optimizing efficient use of space for the achromatic insertions.

Quadrupoles Q219 through Q223 form the final focus (FF) optics to obtain the desired beam size on the target. This final focus is tunable to produce a spot-size of $\sigma=1.00 \rightarrow 3.00 \mathrm{~mm}$ over the entire momentum range $60 \rightarrow 120 \mathrm{GeV} / \mathrm{c}$.

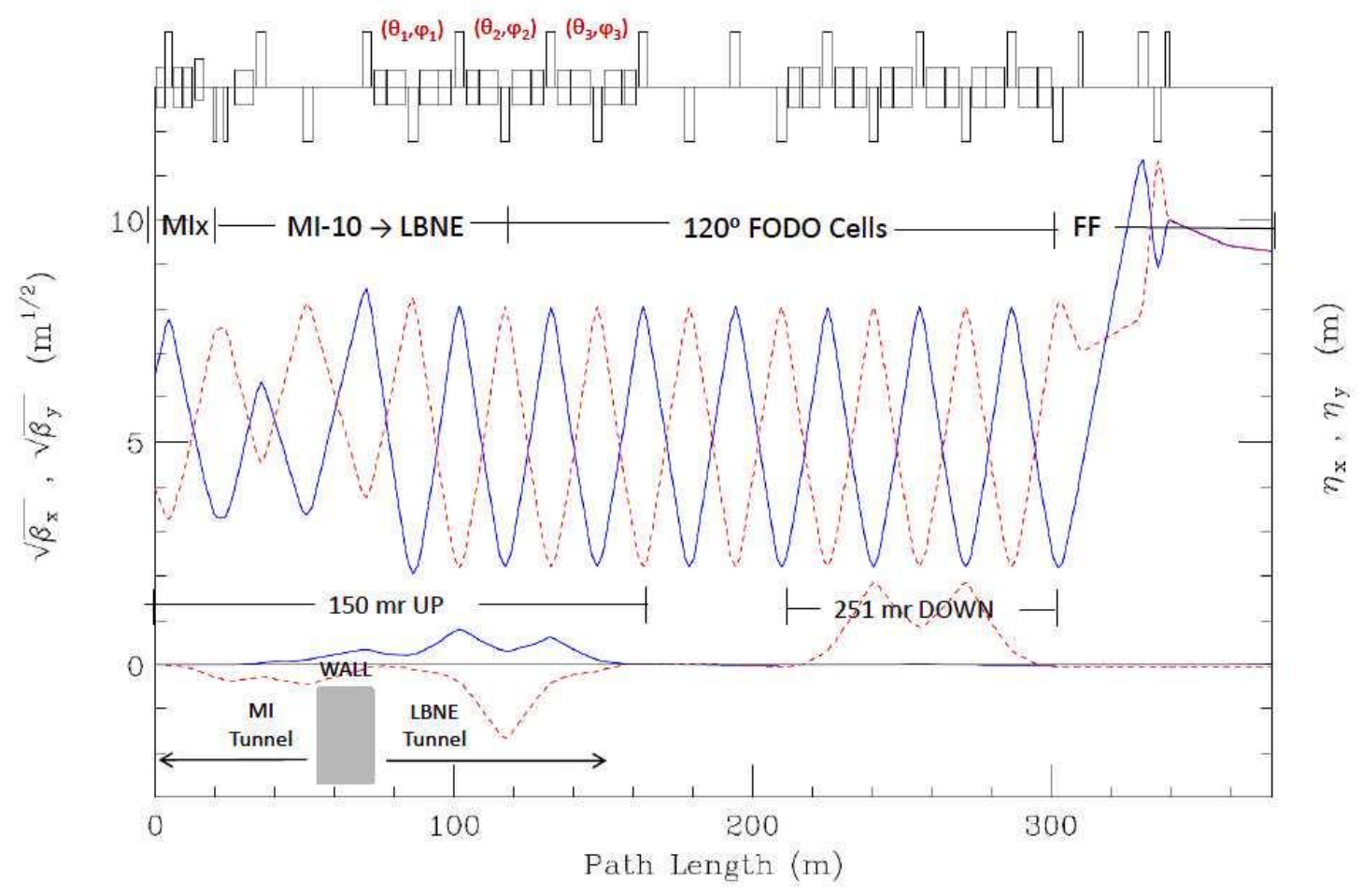

Figure 2: Horizontal (solid) and vertical (dashed) lattice functions of the LBNE transfer line Blue (solid) lattice functions are horizontal; red (dashed) are vertical. Boxes centered along the top axis indicate dipole locations, while boxes extending up $\&$ down are focusing $\&$ defocusing quadrupoles. The final focus is tuned to a spot-size of $\sigma_{\mathrm{x}}=\sigma_{\mathrm{y}}=1.50 \mathrm{~mm}$ at $120 \mathrm{GeV} / \mathrm{c}$ and $\varepsilon=26 \pi \mu \mathrm{m}$ (98\%, normalized) 


\begin{tabular}{|c|c|c|c|c|c|c|c|}
\hline DIPOLE TYPE & $\begin{array}{c}\mathbf{L} \\
(\mathbf{m})\end{array}$ & $\begin{array}{c}\mathbf{B} \\
(\mathbf{T}) \\
\end{array}$ & $\begin{array}{l}\text { TILT } \\
\text { (deg) }\end{array}$ & QUAD NAME & TYPE & $\begin{array}{c}\mathbf{L} \\
(\mathbf{m})\end{array}$ & $\begin{array}{c}\mathbf{G} \\
(\mathbf{T} / \mathbf{m})\end{array}$ \\
\hline \multicolumn{8}{|c|}{ MI-10 EXTRACTION $\rightarrow$ LBNE } \\
\hline \multirow[t]{2}{*}{ MI_LAM } & 2.8000 & 0.5324 & -90.000 & & & & \\
\hline & & & & MI-Q102 & $3 Q 84$ & 2.1336 & +16.16016 \\
\hline MI_LAM & 2.8000 & 1.0000 & -90.000 & & & & \\
\hline MI_LAM & 2.8000 & 1.0000 & -90.000 & & & & \\
\hline C-MAG & 3.3528 & 1.0028 & & & & & \\
\hline \multicolumn{8}{|c|}{ MATCH FROM MI $\rightarrow$ LBNE FODO LATTICE + $150 \mathrm{mr}$ UP BEND } \\
\hline & & & & $\mathrm{Q201A} \rightarrow$ Q201B & $3 Q 60$ & 1.524 & -11.13509 \\
\hline \multirow[t]{4}{*}{ IDA } & 6.09981 & 1.2234 & +62.847 & & & & \\
\hline & & & & Q202 & $3 Q 120$ & 3.048 & +12.48756 \\
\hline & & & & Q203 & $3 Q 120$ & 3.048 & -9.18907 \\
\hline & & & & Q204 & $3 Q 120$ & 3.048 & +13.06221 \\
\hline IDC & 4.06654 & 1.4142 & -45.398 & & & & \\
\hline \multirow[t]{2}{*}{ IDB } & 6.09981 & 1.4142 & -45.398 & & & & \\
\hline & & & & Q205 & $3 Q 120$ & 3.048 & -13.06221 \\
\hline IDA & 6.09981 & 1.4142 & -45.398 & & & & \\
\hline \multirow[t]{2}{*}{ IDD } & 4.06654 & 1.4142 & -45.398 & & & & \\
\hline & & & & Q206 & $3 Q 120$ & 3.048 & +16.16931 \\
\hline IDC & 4.06654 & 1.1362 & -49.440 & & & & \\
\hline IDB & 6.09981 & 1.1362 & -49.440 & & & & \\
\hline \multicolumn{8}{|c|}{$120^{\circ}$ FODO CELLS } \\
\hline & & & & Q207 & $3 Q 120$ & 3.048 & -15.83240 \\
\hline IDA & 6.09981 & 1.1362 & -49.440 & & & & \\
\hline \multirow[t]{2}{*}{ IDD } & 4.06654 & 1.1362 & -49.440 & & & & \\
\hline & & & & Q208 & $3 Q 120$ & 3.048 & +15.83240 \\
\hline IDC & 4.06654 & 1.0343 & -57.288 & & & & \\
\hline \multirow[t]{2}{*}{ IDB } & 6.09981 & 1.0343 & -57.288 & & & & \\
\hline & & & & Q209 & $3 Q 120$ & 3.048 & -15.83240 \\
\hline IDA & 4.06654 & 1.0343 & -57.288 & & & & \\
\hline \multirow[t]{2}{*}{ IDD } & 6.09981 & 1.0343 & -57.288 & & & & \\
\hline & & & & $\mathrm{Q} 210 \rightarrow \mathrm{Q} 213$ & $3 Q 120$ & 3.048 & \pm 15.83240 \\
\hline \multicolumn{8}{|c|}{251 mr ACHROMATIC DOWN BEND } \\
\hline IDC & 4.06654 & 1.6439 & +90.000 & & & & \\
\hline \multirow[t]{2}{*}{ IDD } & 6.09981 & 1.6439 & +90.000 & & & & \\
\hline & & & & Q214 & $3 Q 120$ & 3.048 & +15.83240 \\
\hline IDA & 6.09981 & 1.6439 & +90.000 & & & & \\
\hline \multirow[t]{2}{*}{ IDD } & 4.06654 & 1.6439 & +90.000 & & & & \\
\hline & & & & Q215 & & & -15.83240 \\
\hline IDC & 4.06654 & 1.6439 & +90.000 & & & & \\
\hline \multirow[t]{2}{*}{ IDD } & 6.09981 & 1.6439 & +90.000 & & & & \\
\hline & & & & Q216 & $3 Q 120$ & 3.048 & +15.83240 \\
\hline IDA & 6.09981 & 1.6439 & +90.000 & & & & \\
\hline \multirow[t]{2}{*}{ IDD } & 4.06654 & 1.6439 & +90.000 & & & & \\
\hline & & & & Q217 & & & -15.83240 \\
\hline IDC & 4.06654 & 1.6439 & +90.000 & & & & \\
\hline \multirow[t]{2}{*}{ IDD } & 6.09981 & 1.6439 & +90.000 & & & & \\
\hline & & & & Q218 & $3 Q 120$ & 3.048 & +15.83240 \\
\hline IDA & 6.09981 & 1.6439 & +90.000 & & & & \\
\hline IDD & 4.06654 & 1.6439 & +90.000 & & & & \\
\hline \multicolumn{8}{|c|}{ FINAL FOCUS to $\beta^{*}=86.3 \mathrm{~m}(\sigma=1.50 \mathrm{~mm} @ 120 \mathrm{GeV} / \mathrm{c})$} \\
\hline & & & & Q219 & $3 Q 120$ & 3.048 & -10.88170 \\
\hline & & & & Q220 & $3 Q 60$ & 1.524 & +6.88602 \\
\hline & & & & Q221 & $3 Q 120$ & 3.048 & +12.35390 \\
\hline & & & & Q222 & $3 Q 120$ & 3.048 & -16.81837 \\
\hline & & & & Q223 & $3 Q 120$ & 3.048 & +13.98115 \\
\hline
\end{tabular}

Table 1: Magnet parameters of the LBNE proton beamline at $120 \mathrm{GeV} / \mathrm{c}$ and $\beta^{*}=86.33 \mathrm{~m}$ 
Magnet apertures (including the impact of rolls) and beam envelopes at $60 \& 120 \mathrm{GeV} / \mathrm{c}$ are shown in Figure 3. One contour corresponds to nominal MI beam parameters of $\varepsilon=26 \pi \mu \mathrm{m}(98 \%$, normalized) and $\Delta \mathrm{p}_{98} / \mathrm{p}=9$.e-4. The larger envelopes shown are calculated for $\varepsilon=360 \pi \mu \mathrm{m}(100 \%$, normalized) and $\Delta \mathrm{p}_{100} / \mathrm{p}=28$.e-4. These latter values reflect the admittance of the Main Injector at transition $\left(\gamma_{t}=21.600\right)$, and the transfer of such a beam to LBNE could only result from a catastrophic failure of the MI and LBNE safety and regulatory systems. The maximum transverse emittance of $360 \pi$ is determined by the restricted horizontal aperture seen by the circulating MI beam in the Lambertson magnets. The maximum momentum spread is the value that can be contained in an RF bucket through acceleration. The $\varepsilon=360 \pi \mu \mathrm{m} \& \Delta \mathrm{p}_{100} / \mathrm{p}=28$.e-4 envelopes, therefore, demonstrate that the LBNE beamline should be able to transport, without losses, the worst quality beam that the Main Injector could conceivably transmit.

$60 \mathrm{GeV} / \mathrm{c}$ Beam Envelope \& Magnet Apertures

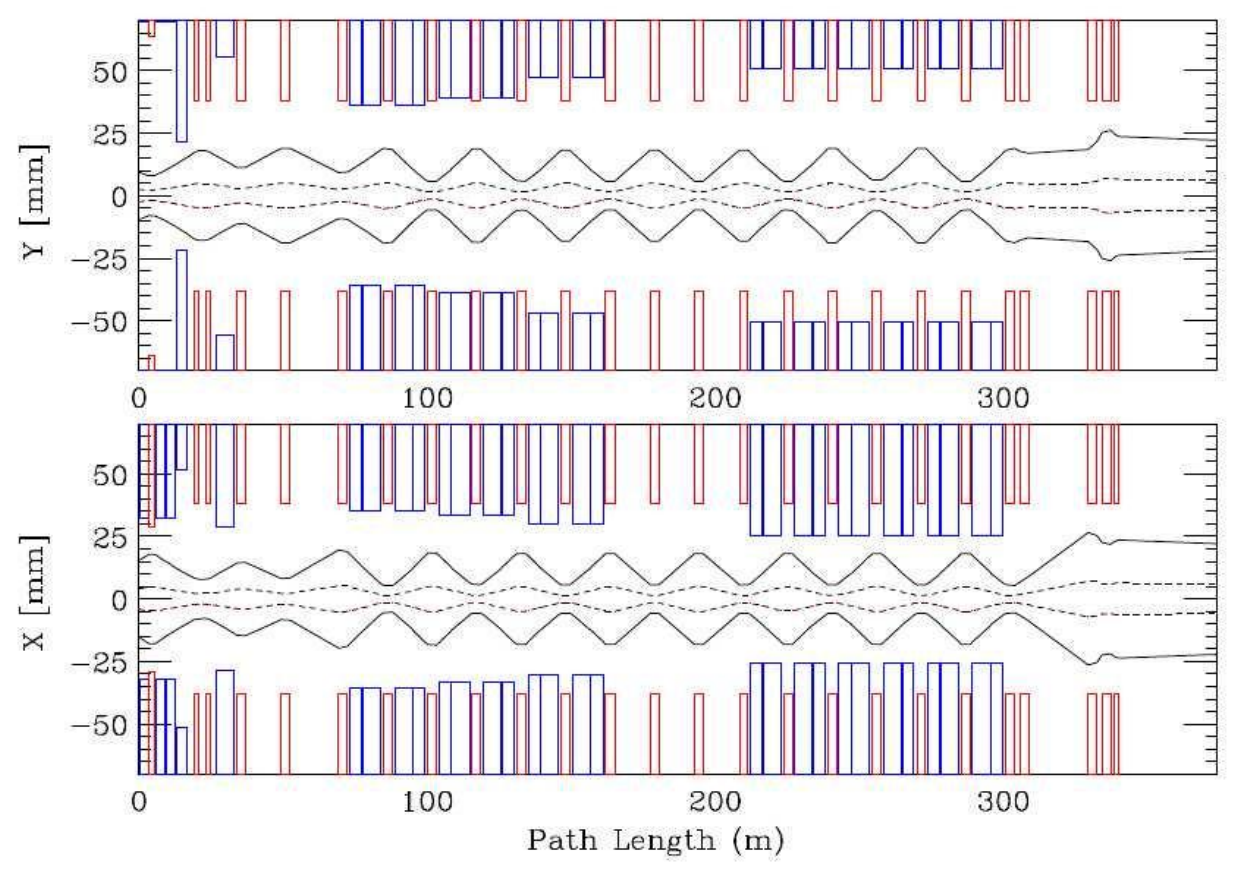




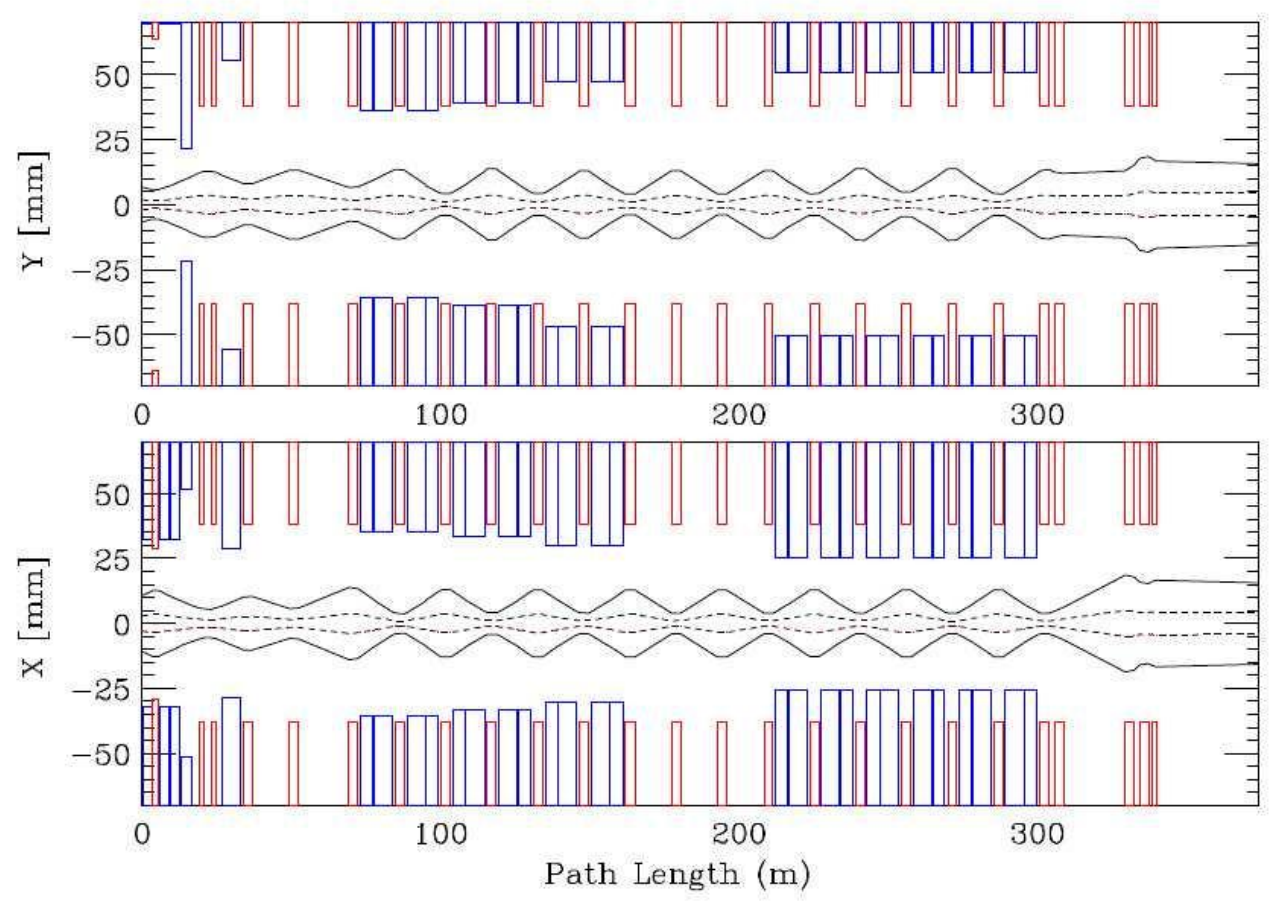

Figure 3: Magnet apertures and beam envelopes at $60 \mathrm{GeV} / \mathrm{c}$ (top) \& $120 \mathrm{GeV} / \mathrm{c}$ (bottom)

The $98 \%$ contour (dashed) with nominal MI beam parameters, and; the $100 \%$ envelope (solid) corresponding to the $\mathrm{Ml}$ admittance at transition $\left(\gamma_{\mathrm{t}}=21.600\right)$. Blue boxes along the top $\&$ bottom axes indicate the available dipole apertures; red boxes are quadrupole apertures.

\section{Sensitivity to Gradient Errors}

There is every reason for confidence that the optical integrity of the LBNE beamline will not be compromised by magnet-to-magnet variations in the integrated quadrupole fields. Experience with the MI-style 3Q120 magnets has shown that these magnets are of very high accelerator quality, with a spread in gradient errors on the order of $\sigma(\Delta G / G) \sim 0.08 \%$ or less [5]. Such a narrow error distribution cannot appreciably impact the beam characteristics or transport capabilities. Implementing even the most rudimentary strategy for sorting production quadrupoles, such as selecting those from the middle of the distribution for installation in the FODO cells, will reduce the spread even further. For nominal beam parameters at $120 \mathrm{GeV} / \mathrm{c}$, a simple thin-lens calculation predicts that the largest error-wave expected in the $98 \%$ beam envelope $( \pm 3.62 \mathrm{~mm}$ nominal at $\beta=$ $64.5 \mathrm{~m}$ ) would be less than 68 microns.

\section{Beam Size on Target}

An essential design requirement of the FF is the ability to tune the spot-size $\sigma$ over a wide range. The optimum spot-size at $700 \mathrm{~kW}$ beam power is believed to fall in the range $\sigma \sim 1.5-2.0 \mathrm{~mm}$, which would grow to $\sim 2.5-3.0 \mathrm{~mm}$ for a $2.3 \mathrm{MW}$ upgrade. Spot-size is still an evolving parameter, however. Ultimately, the choice will be driven to a large extent by details of the final target design, but other factors must also be considered. In addition to the $40 \%$ difference in beam size between 
60 and $120 \mathrm{GeV} / \mathrm{c}$, under realistic operational conditions the beam parameters $(\varepsilon, \Delta \mathrm{p} / \mathrm{p})$ will almost certainly be different from the ideal nominal values assumed here. Currently, the MI emittance at $120 \mathrm{GeV} / \mathrm{c}$ is $\sim 20 \pi$, but it is not clear how this value might develop in the future. It is essential that the FF design be sufficiently robust \& versatile to anticipate these possibilities.

Figure 4 illustrates the wide tuning range of the FF. Results are shown for the 2 extremes of operational requirements. Calculations were performed assuming nominal beam parameters but the plot demonstrates that the FF is clearly adaptable to any reasonable set of beam parameters. To meet the 2 extremes of spot-size criteria considered here $\beta^{*}$ at the target must be continuously tunable over a range of $\mathrm{x} 18$. The corresponding quadrupole gradients are listed in Table 2 . The advantages of a modular optics design are evident — variations in the extracted MI beam parameters can be accommodated solely within the FF \& do not involve tuning adjustments elsewhere in the line.

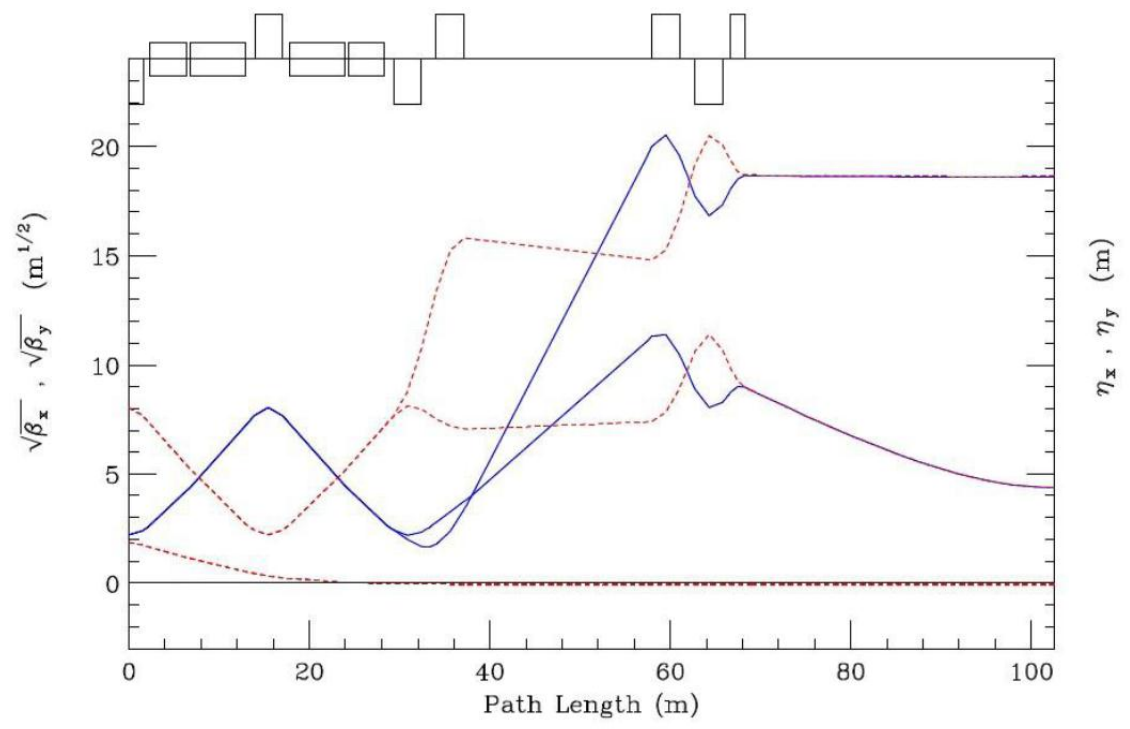

Figure 4: Tuning range of the Final Focus

These extremes of tuning range assume nominal MI beam parameters. $\beta^{*}$ varies by a factor $\times 18$. At $60 \mathrm{GeV} / \mathrm{c}$ and $\sigma=1.0 \mathrm{~mm} ; \beta^{*}=19.184 \mathrm{~m} \mathrm{\&} \beta \max =130 \mathrm{~m}$. At $120 \mathrm{GeV} / \mathrm{c}$ and $\sigma=3.00 \mathrm{~mm}$; $\beta^{*}=345 \mathrm{~m} \& \beta \max =420 \mathrm{~m}$.

\begin{tabular}{|c|c|c|c|c|}
\cline { 3 - 4 } \multicolumn{2}{c|}{} & $\begin{array}{c}\sigma=1.00 \mathrm{~mm} @ 60 \mathrm{GeV} / \mathrm{c} \\
\beta^{*}=19.184 \mathrm{~m}\end{array}$ & $\begin{array}{c}\sigma=3.00 \mathrm{~mm} @ 120 \mathrm{GeV} / \mathrm{c} \\
\beta^{*}=345.31 \mathrm{~m}\end{array}$ \\
\hline QUAD & TYPE & $\begin{array}{c}\mathrm{L} \\
(\mathrm{m})\end{array}$ & $\begin{array}{c}\mathrm{G} \\
(\mathrm{T} / \mathrm{m})\end{array}$ & $\begin{array}{c}\mathrm{G} \\
(\mathrm{T} / \mathrm{m})\end{array}$ \\
\hline Q219 & $3 Q 120$ & 3.048 & -6.21424 & +16.33683 \\
\hline Q220 & 3060 & 1.524 & +2.31123 & -14.33993 \\
\hline Q221 & $3 Q 120$ & 3.048 & +10.46613 & +12.13973 \\
\hline Q222 & 30120 & 3.048 & -11.31659 & -14.41450 \\
\hline Q223 & 3060 & 1.524 & +7.62203 & +11.53926 \\
\hline
\end{tabular}

Table 2: Final Focus gradients for the examples in Figure 3. 


\section{Trajectory Correction}

Orbit correction is an issue which, of course, must be addressed in the design of any transfer line, but for the ultra-clean transport requirements of LBNE it is critical that precise position control be available throughout the beamline.

Correction of central trajectory errors have been simulated for dipole field errors and random misalignments assigned to all beamline elements (including BPM's). Realistic error values are on the order of $\sigma(\Delta \mathrm{x}, \Delta \mathrm{y})=0.25 \mathrm{~mm}$, and $\sigma(\psi$ roll $)=0.50 \mathrm{mr}$ [6]. Figure 5 shows the trajectory deviations resulting from randomly generated Gaussian error distributions (dashed). Also shown are the corrected orbits (solid), illustrating the efficient reduction in offset errors. Results of the tracking are summarized in Table 3. All corrector strengths are well within the $250 \mu \mathrm{r}(60 \%$ of peak) design specification for the new IDS trims.

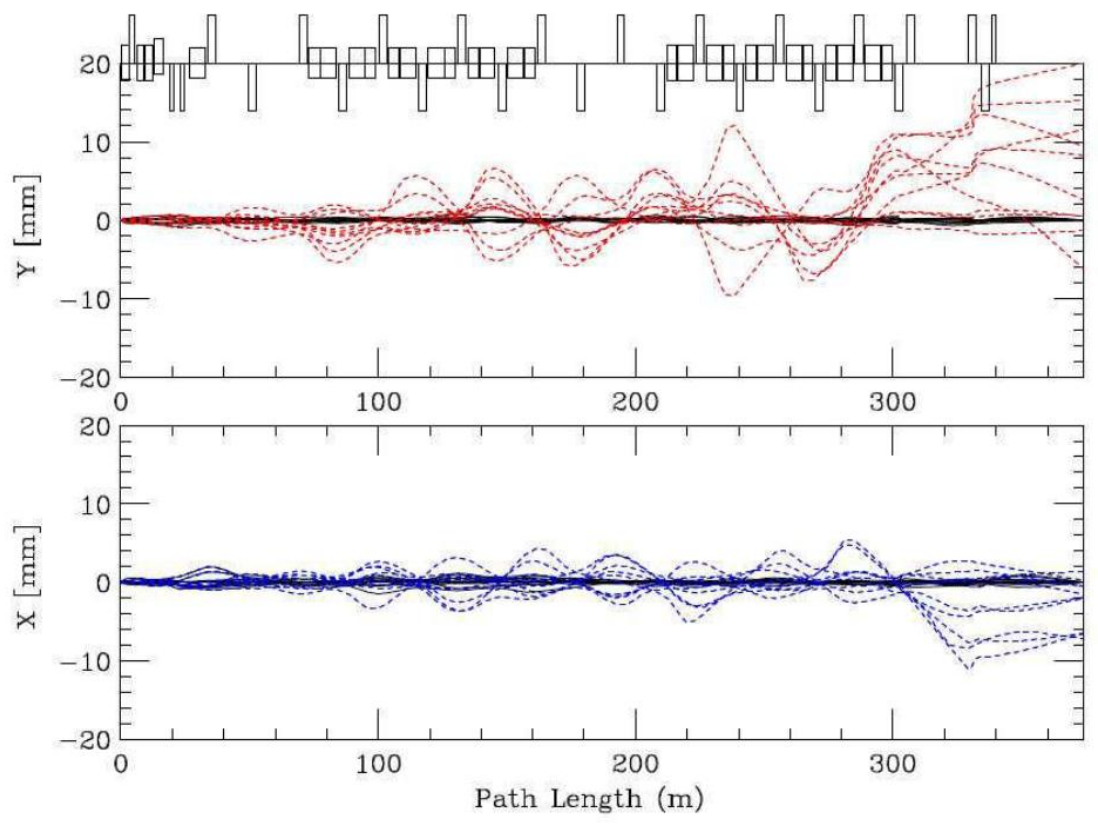

Figure 5: Uncorrected/corrected trajectories with random misalignments and dipole field errors The plot begins at the $\mathrm{u} / \mathrm{s}$ end of the $1^{\text {st }}$ extraction Lambertson at MI-Q102.

\begin{tabular}{|c|c|c|c|c|c|c|c|c|}
\hline & \multicolumn{2}{|c|}{$\begin{array}{l}\text { ORBIT } \\
(\mathrm{mm})\end{array}$} & \multicolumn{2}{|c|}{$\begin{array}{l}\text { CORRECTORS } \\
(\mu \mathrm{r})\end{array}$} & \multicolumn{2}{|c|}{$\begin{array}{l}\text { ORBIT } \\
(\mathrm{mm})\end{array}$} & \multicolumn{2}{|c|}{$\begin{array}{c}\text { CORRECTORS } \\
(\mu \mathrm{r})\end{array}$} \\
\hline & $x_{\max }$ & $\mathrm{X}_{\mathrm{RMS}}$ & $\theta_{\max }$ & $\theta_{\text {RMS }}$ & $Y_{\max }$ & $\mathrm{Y}_{\mathrm{RMS}}$ & $\varphi_{\max }$ & $\varphi$ RMS \\
\hline UNCORRECTED & 11.012 & 2.179 & - & - & 19.991 & 4.444 & - & - \\
\hline \multirow[t]{4}{*}{ CORRECTED } & 1.885 & 0.376 & 85.382 & 27.955 & 0.806 & 0.255 & 82.467 & 31.511 \\
\hline & \multicolumn{8}{|c|}{ BEAM JITTER ON TARGET } \\
\hline & \multicolumn{2}{|c|}{$\begin{array}{c}X \\
(\mu \mathrm{m})\end{array}$} & \multicolumn{2}{|c|}{$\begin{array}{c}X^{\prime} \\
(\mu r)\end{array}$} & \multicolumn{2}{|c|}{$\begin{array}{c}Y \\
(\mu \mathrm{m})\end{array}$} & \multicolumn{2}{|c|}{$\begin{array}{c}Y^{\prime} \\
(\mu \mathrm{r})\end{array}$} \\
\hline & $X_{\max }$ & $\mathrm{X}_{\mathrm{RMS}}$ & $\mathrm{X}_{\text {max }}^{\prime}$ & $\mathrm{X}_{\mathrm{RMS}}^{\prime}$ & $Y_{\max }$ & $\mathrm{Y}_{\mathrm{RMS}}$ & $Y_{\text {max }}^{\prime}$ & $\mathrm{Y}_{\mathrm{RMS}}$ \\
\hline CORRECTED & 2.656 & 1.586 & 1.265 & 0.751 & 1.955 & 0.942 & 0.625 & 0.306 \\
\hline
\end{tabular}

Table 3: Orbit offsets and corrector kicks for the trajectories in Figure 4. 
The (relatively) large residual value of $\mathrm{X} \max$ is an unrealistic artifact of the simulation model. For one random generator seed badly misaligned quadrupoles $[\Delta \mathrm{x}>3 \sigma(\Delta \mathrm{x})]$ at the beginning of the line produced the spike at Q202, and the Q201 vertical correctors could have no impact. In reality, a horizontal trim would probably be added to Q201's complement, or the errant quadrupole would simply be realigned. Beam position on the target is accurate to a few microns - far below the 150 $\mu \mathrm{m}$ tolerance set by horn focusing. The worst angular error found is $\sim 1.4 \mu \mathrm{r}$ which, 800 miles away at the Far Detector, translates into $\sim 6 \mathrm{ft}$ of position error, which is clearly negligible.

The fact that the orbit deviations are virtually the same in both planes indicates that quadrupole misalignments are the dominant source of errors. A $15 \mathrm{~T} / \mathrm{m}$ quadrupole displaced transversely by $0.25 \mathrm{~mm}$ produces a kick $\sim 30 \mu \mathrm{r}$ which is larger than the angular error resulting from $\Delta \mathrm{B} / \mathrm{B}=10 . \mathrm{E}-4$ in any of the beamline's dipoles.

\section{Summary}

The LBNE beamline discussed here is a modular optics design comprised of 3 distinct lattice configurations, including the specialized MI $\rightarrow$ LBNE matching section \& Final Focus. The remainder of the line is defined by six FODO cells, in which the length \& phase advance are chosen specifically such that beam size does not exceed that of the MI while also making the most efficient use of space for achromatic insertions. Dispersion generated by variations in the beam trajectory are corrected locally and can not bleed out to corrupt the optics elsewhere in the line. Aperture studies indicate that the line should be able to transport the worst quality beam that the Main Injector might provide. New IDS dipole correctors located at every focusing center provide high-quality orbit control \& further ensure that LBNE meets the stringent requirements for environmental protection.

\section{Acknowledgements}

The authour welcomes this opportunity to thank his friends \& colleagues in the Accelerator Physics Center, Accelerator Division, Technical Division, Mechanical \& Electrical Engineering, Alignment \& Metrology, and the LBNE Project Management for many lively \& entertaining discussions.

\section{References}

[1] “LBNE Conceptual Design Report (vol. 2) - Neutrino Beamline”, Sub-section 2.2.2.1.

[2] Ibid., Sub-section 2.2.2.4 \& 2.2.2.5.

[3] Ibid., Sub-section 2.2.2.6.

[4] Ibid., Sub-section 2.5.2.1.

[5] David Harding (private communication) and; MTF measurement database.

[6] Virgil Bocean (private communication).

\section{$\Omega$}

